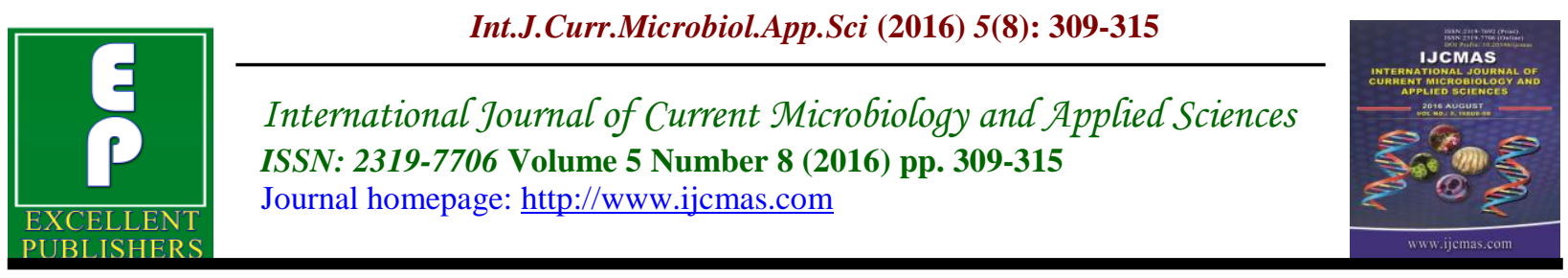

Original Research Article

http://dx.doi.org/10.20546/ijcmas.2016.508.033

\title{
Optimization of Fermentation Processes for Higher Poly Galacturonase Production from Various Soil Bacteria
}

\author{
Sanjay Patel ${ }^{1 *}$, Dipika Pandya ${ }^{2}$ and S.A. Bhatt ${ }^{2}$ \\ ${ }^{1}$ Department of plant pathology, College of Agriculture, Navsari Agricultural University, \\ Bharuch Campus, Bharuch, India \\ ${ }^{2}$ Department of Life sciences, Hemchandracharya North Gujarat University, Patan, India \\ *Corresponding author
}

Keywords

Pectinase, galacturonic acid, polygalacturonase (PGase), ammonium sulphate, urea,

Submerged fermentation $(\mathrm{SmF})$, solid-state fermentation (SSF).

Article Info

Accepted:

17 July 2016 Available Online:

10 August 2016

\section{A B S T R A C T}

Pectinases are the various hydrolytic and depolymerizing enzymes that breakdown pectin fibre. They have diverse application in field of food industry, pharmaceutical industry and waste management. Pectinases are produced from almost all organisms including microbes, plant and animals. Pectinases from the fungal and bacterial origin is considerably more important for commercial production. Isolation of polygalacturonase producing bacterial species is carried out from the soil which is dumped with fruits and vegetables. The production of polygalacturonase by different soil isolates are optimized under submerged fermentation conditions. Nutritional and physical factors that influence polygalacturonase production are optimized by one factor at a time (OFAT) method in order to achieve high yield of polygalacturonase. In present study, production of polygalacturonase is enhanced by modifying various physic-chemical parameters. Different nitrogen sources and their varied concentration affect enzyme activities. Pectin concentration, $\mathrm{pH}$ of the medium, vitamins and amino acid concentration is also affect polygalacturonase production. For the assay of polygalacturonase enzyme polgalacturonic acid are used and the liberated galacturonic acid is measured by Di-Nitro Salicylic acid method. Among various nitrogen sources ammonium sulphate enhance polygalacturonase production and at slightly acidic $\mathrm{pH}$ enzyme activities is also observed higher.

\section{Introduction}

The biotechnological potential of pectinolytic enzymes from microorganisms has drawn a great deal of attention from various researchers world-wide as likely biocatalysts in a variety of industrial processes. Alkaline pectinases are among the most important industrial enzymes having great significance in the current biotechnological arena with wide ranging applications in the textile processing, treatment of pectic waste waters, paper making and coffee and tea fermentations (Hoondal et al., 2002). The enzyme preparations used in industry are of bacterial and fungal origin. Pectic enzymes are available in dry powdered as well as in 
liquid form. Now a days interest in thermostable liquid enzymes has developed as they are associated with many benefits (Sharma et al., 2011). They are nonpolluting biochemical catalysts which are safe and easy to use.

The synthesis of these enzymes by microorganisms has been reported to be highly influenced by factors such as carbon sources, temperature, $\mathrm{pH}$, and operating parameter such as incubation time in submerged culture (Jacob et. al., 2006; Palaniyappan et al., 2009). Factors like carbon, nitrogen sources and their concentrations have always been of great interest to researchers in the industry for the low-cost media design. It is also known that $30-40 \%$ of the production cost of industrial enzymes is estimated to be the cost of growth medium. Therefore, it is of great significance to optimize the conditions for cost-efficient enzyme production.

Submerged fermentation $(\mathrm{SmF})$ and solidstate fermentation (SSF) processes have been widely used for PGase production by different types of microorganisms. SSF is considered more suitable for fungi than for bacteria and yeast (Raimbault et al., 1998 and Pandey, 2003). PGase production by Streptomyces sp. QG-11-3 increased 5.6fold when grown in a culture medium supplemented with L-leucine and DLisoleucine (Beg et al., 2000).

Similarly, addition of amino acids (DLserine and DL-ornithine) to the culture medium in SmF and SSF enhanced (4.0 and 5.7 times, respectively) the PGase production by Bacillus sp. MG-cp-2. Kashyap et al., (2003) demonstrated that the addition of multivitamin additive Neurobion (mixture of B1, B6, and B12) to the culture medium increased 1.75-fold the pectinase production by Bacillus sp. DT7 in a SSF system.

\section{Materials and Methods}

Isolation of pectin degrading
microorganism

Isolation of pectin degrading microorganisms are carried out in the medium having pectin as a sole carbon source. More than 45 bacterial strains are isolated from the vegetable and fruit market's soil. Among these potential producers are selected for the optimization of pectinase production.

\section{Enzyme assay}

Pectinases act on pectin (polygalacturonic acid) and liberate galacturonic acid, a reducing sugar, easily estimated by Di-Nitro Salicylic acid method (Miller, 1959). Polygalacturonase activity has been determined by using $0.5 \%$ polygalacturonic acid substrate prepared in $0.1 \mathrm{M}$ acetate buffer ( $\mathrm{pH}-5.0)$.

Polygalacturonase production was carried out in the medium having following composition: pectin(citrus pectin); $1 \%$, $\left(\mathrm{NH}_{4}\right)_{2} \mathrm{SO}_{4} ; \quad 0.14 \%, \quad \mathrm{~K}_{2} \mathrm{HPO}_{4} ; \quad 0.6 \%$, $\mathrm{KH}_{2} \mathrm{PO}_{4} ; 0.2 \%, \mathrm{MgSO}_{4} .7 \mathrm{H}_{2} \mathrm{O} ; 0.01 \%$ and yeast extract; $1 \%$.

Polygalacturonase activity is determined at different $\mathrm{pH}$ for selected strains. Fermentation medium with different $\mathrm{pH}$ are prepared (pH-4.0, 5.0, 7.0, 8.0 and 9.0). $\mathrm{pH}$ of the media are adjusted to required value with $0.1 \mathrm{~N}$ acetic acid and/or $0.1 \mathrm{~N} \mathrm{NaOH}$.

Effect of pectin substrate was checked by using different concentration $(0.0 \%, 0.5 \%$, $2.0 \%, 3.0 \%)$. The results of effect of concentration of pectin on polygalacturonase production are shown in graph. In the present study Ammonium sulphate, urea and ammonium chloride with different 
concentration have been tested for polygalacturonase production.

\section{Result and Discussion}

\section{Effect of pH on polygalacturonase activity}

Polygalacturonase activity considerably reduced at higher or lower $\mathrm{pH}$ values. $\mathrm{pH}$ 9.0 and $\mathrm{pH} \quad 4.0$ severely affect polygalacturonase activity and no remarkable activity has been obtained after this point. Certain bacterial strains showed good activity in slightly acidic $\mathrm{pH}$ range. Isolates Pect 10, Pect 16 and Pect 29 have retained their enzymatic potential at $\mathrm{pH} 5.0$ and for these isolates this is the optimum $\mathrm{pH}$ where they showed 7.32, 7.78 and 6.86 unit activity.

In the alkaline range of $\mathrm{pH}$ none of the isolates gave good polygalacturonase activity.

\section{Effect of substrate on polygalacturonase activity}

Polygalacturonase enzyme produced even in the absence of pectin. But the presence of substrate increases the polygalacturonase production. All the isolate have shown increased production of Polygalacturonase in presence of pectin. Thus, it is seen that though enzyme is constitutive in nature, presence of pectin enhances the production of polygalacturonase. It is also seen that at $3 \%$ of substrate concentration polygalacturonase production is not increased remarkably and seems to be remain constant in some cultures. Therefore, $3 \%$ substrate may be optimum for these cultures.

\section{Graph.1 Effect of $\mathrm{pH}$ on polygalacturonase activity}

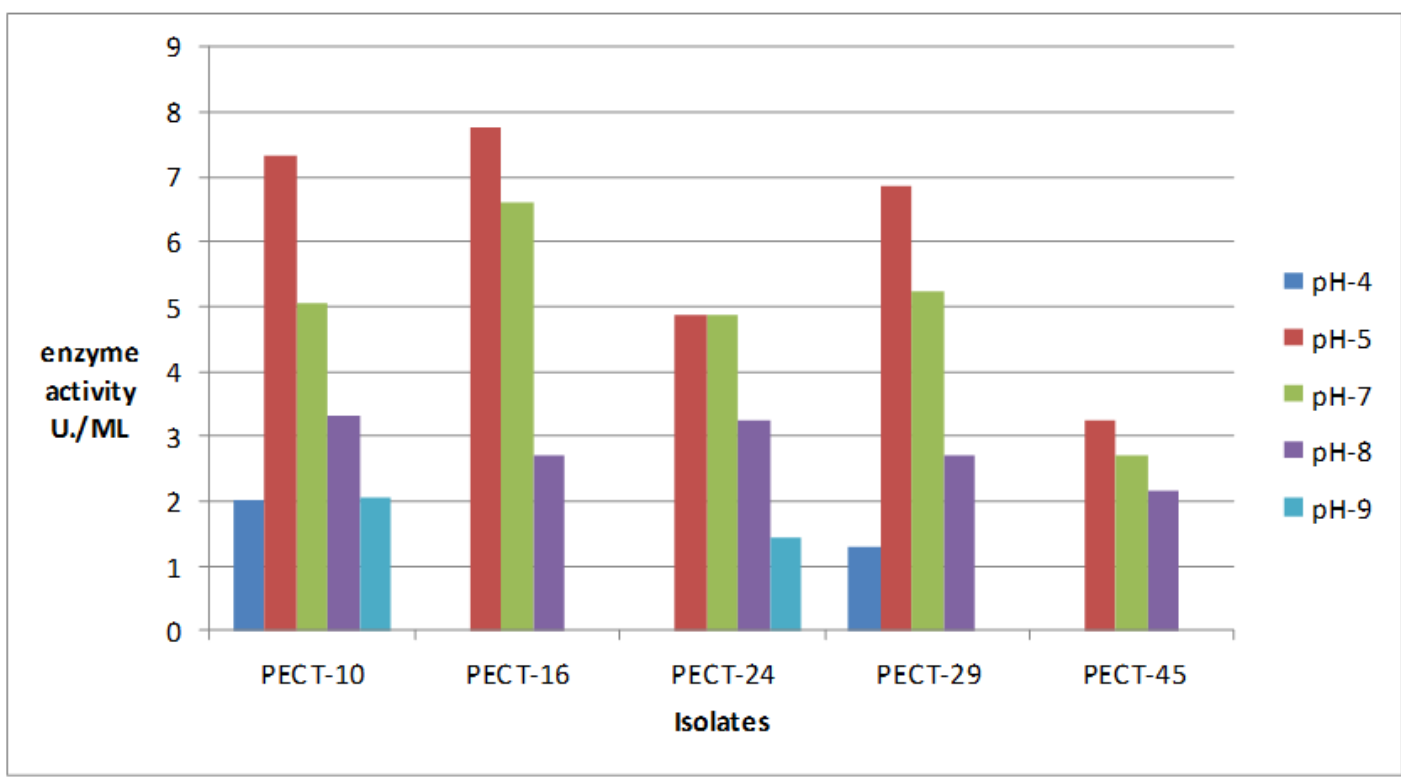


Graph.2 Effect of substrate on polygalacturonase activity

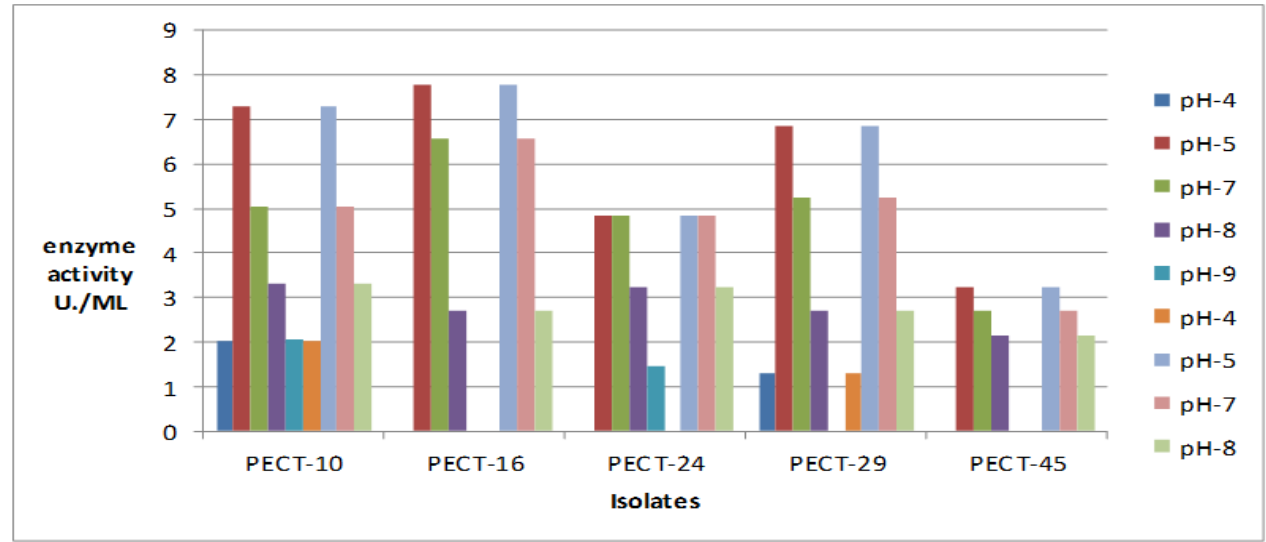

Graph.3.1 Effect of different Nitrogen source on polygalacturonase activity of PECT-10

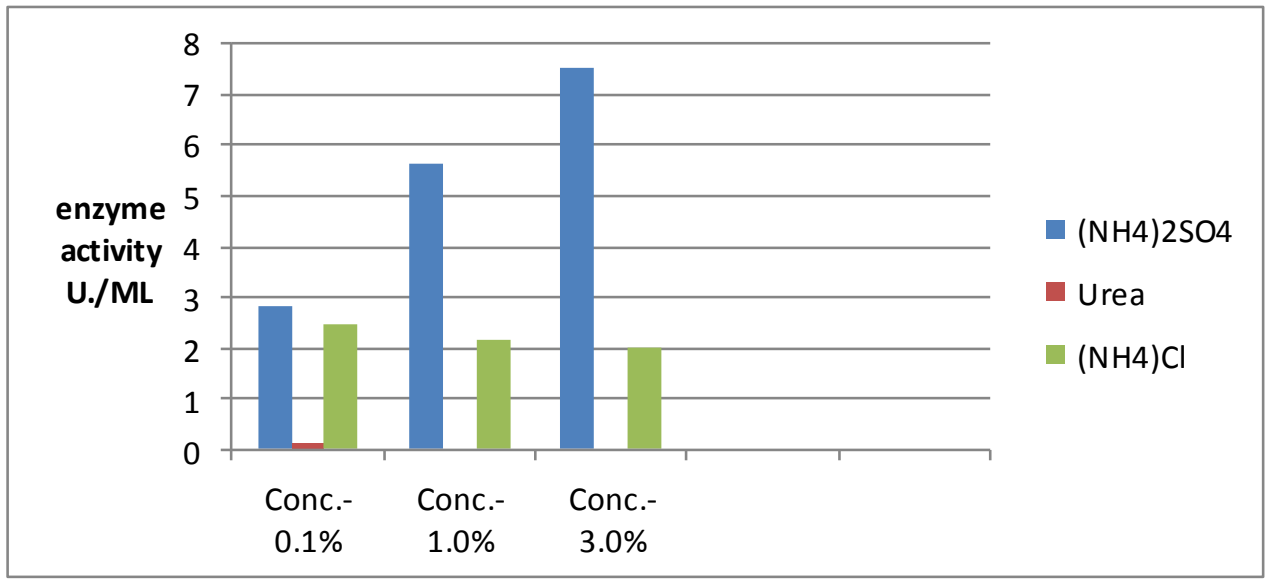

Graph.3.2 Effect of different Nitrogen sources on polygalacturonase activity of PECT-16

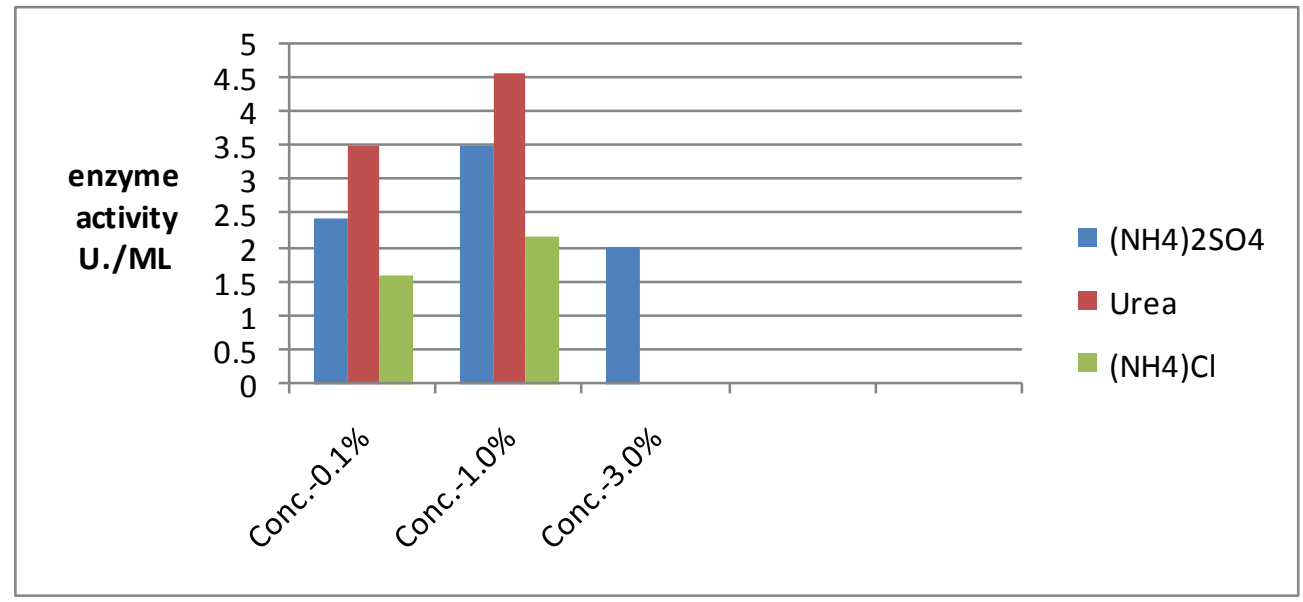


Graph.3.3 Effect of different Nitrogen sources on polygalacturonase activity of PECT-24

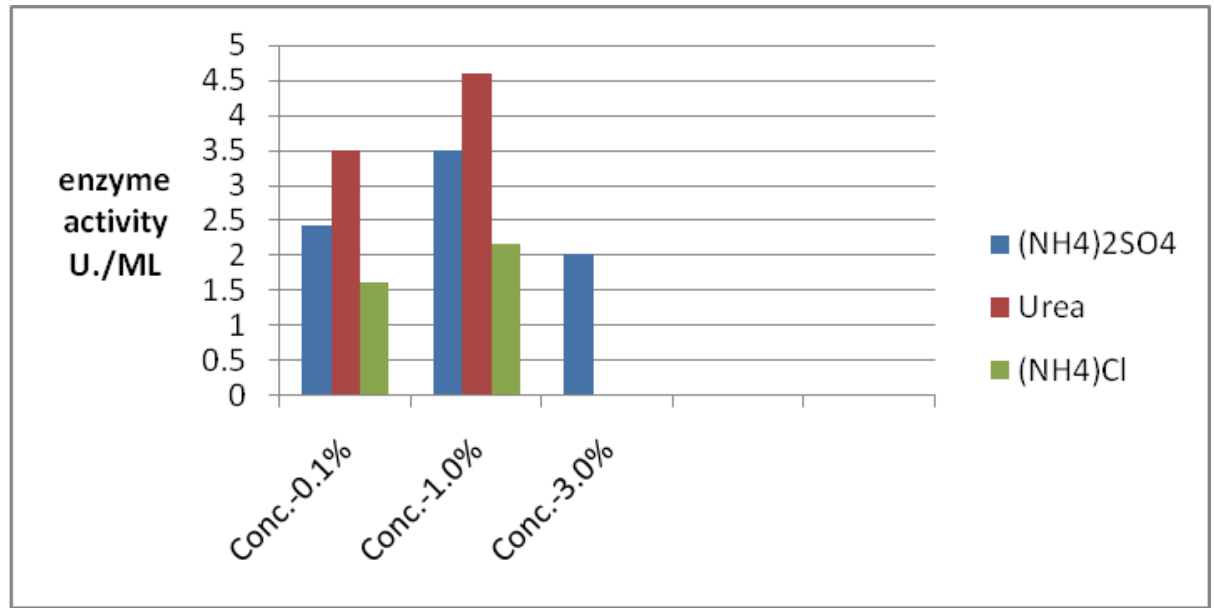

Graph.3.4 Effect of different Nitrogen sources on polygalacturonase activity of PECT-29

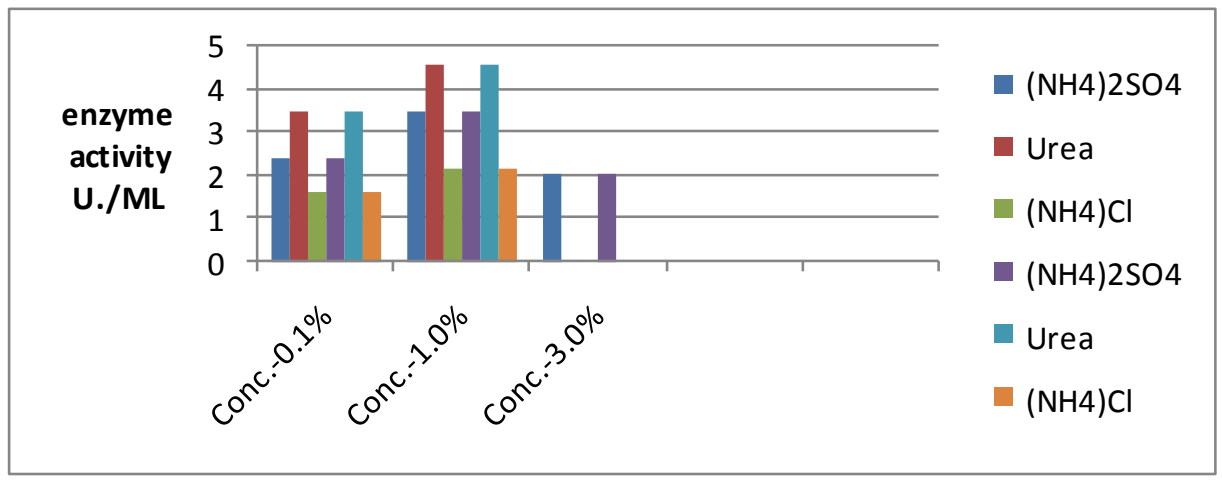

Graph.3.5 Effect of different Nitrogen sources on polygalacturonase activity of PECT-45

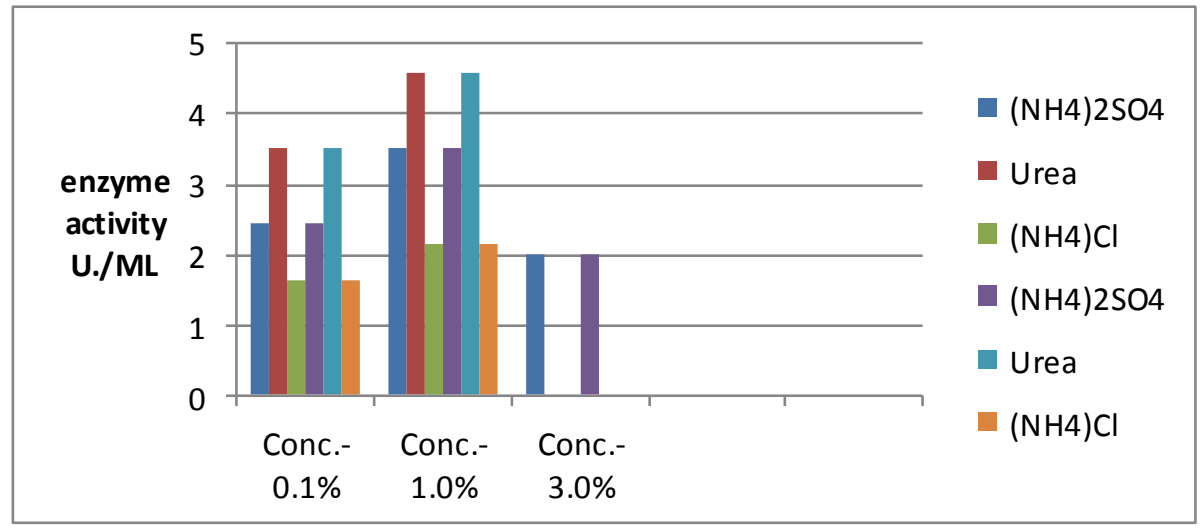

Effect of different Nitrogen source on polygalacturonase activity

Effect of nitrogen sources on the polygalacturonase production are shown in graph 3.1 to 3.5 which indicates that increasing ammonium sulphate concentration induces higher enzyme activity. In isolates PECT-10, PECT-16 and PECT-29, polygalacturonase activity is increased remarkably with the increase in biomass production. In PECT-24 and PECT- 
45 biomass concentration and polygalacturonase activity are observed upto $1 \%$ ammonium sulphate concentration but at $3 \%$ concentration both are reduced indicates higher concentration of ammonium sulphate may have negative impact on growth and polygalacturonase production. Urea is not growth supportive nitrogen source as compared to ammonium sulphate. At $0.1 \%$ concentration of urea biomass and polygalacturonase production is observed in PECT-1, PECT-24, PECT-29 and PECT-45 (see graph 3.1to 3.5). PECT-10 does not respond to any of the concentration of urea provided. At 3\% concentration of urea, polygalacturonase activity is sharply reduced in isolates PECT-10, PECT-16 and PECT-24. Increasing in urea concentration also reduced biomass production. Ammonium chloride also affects polygalacturonase production; it shows similar effect as urea at higher concentration. It reduces production of biomass and also polygalacturonase. In isolate PECT-16 and PECT-24, enzyme activity is increased as ammonium chloride concentration is increased from $0.1 \%$ to $1.0 \%$. In rest of isolates polygalacturonase activity is reduced with increased ammonium chloride concentration. Only in PECT-29 polygalacturonase activity is enhanced at $3 \%$ ammonium chloride concentration. Results indicate that ammonium sulphate is better nitrogen source for the biomass as well polygalacturonase production compare to urea and ammonium chloride. However, it seems that different isolates respond differently with varied nitrogen source and hence for every strain the nutrients are to be standardized for industrial applications. No single nitrogen source can be taken as universal for production of polygalacturonase enzyme. PECT-10 and PECT-16 gave best response for polygalacturonase production at $3 \%$ concentration (see graph 3.1to 3.5). However, urea seems to be the preferred nitrogen source after ammonium sulphate by cultures in the present study.

Optimization study showed change in the medium ingredient affect the pectinase production. Among this presence of different nitrogen sources with different concentration significantly affect the enzyme production. Change in the pectin concentration also affects the pectinase activity. Higher pectin concentration promotes the higher production of pectinase. Ammonium sulphate is good nitrogen source for the pectinase production and their higher concentration has also promoted the enzyme production.

$\mathrm{pH}$ play important role in maintaining the active configuration of enzymes, pectinase is sensitive to $\mathrm{pH}$ change. Pectinase production is reduced at extreme $\mathrm{pH}$ but the production is not much altered at the slightly acidic $\mathrm{pH}$. Neutral $\mathrm{pH}$ gave pectinase activity but enzyme remains more active at slight acidic range. Alkaline $\mathrm{pH}$ Is not much more supportive for pectinase production. Enzyme stability in acidic $\mathrm{pH}$ range is important because the Juice which is subject to clarification have acidic nature.

\section{References}

Aiyer, V.P. 2005. Amylases and their applications. African J. Biotechnol., 4(13): 1525-1529.

Akhilesh, T., Pahwa, R., Singh, S. and Gupta, R. 2010. Production, purification, and characterization of polygalacturonase from Mucorcircinelloides ITCC 6025, Enzyme Res., Article ID 170549, 7.

Alonso, D.O. and Dill, K.A. 1991. Solvent denaturation and stabilization of globular proteins. Biochem., 30(24): 
5974-5985.

Beg, Q.K., B. Bhushan, M. Kapoor, G.S. Hoondal, 2000. Effect of amino acids on production of xylanase and pectinase from Streptomyces sp. QG11-3, World J. Microbiol. iotechnol. 16, 211-213.

Hoondal, G.S., Tiwari, R.P., Tewari, R., Dahiya, N. and Beg, Q.K., 2002. Microbial alkaline pectinases and their industrial applications: a review. Appl. Microbiol. Biotechnol., 59: 409-418.

Jacob, N. and Prema, P. 2006. "Influence of mode of fermentation on production of polygalacturonase by a novel strain of Streptomyces lydicus," Food Technol. Biotechnol., 44(2): 263-267.

Jayani, R.S., Saxena, R. and Gupta, R. 2005. "Microbial pectinolytic enzymes: a review," Process Biochem., 40(9): 2931-2944.

Kashyap D.R., S.K. Soni, R. Tewari. 2003. Enhanced production of pectinase by Bacillus sp. DT7 using solid-state fermentation, Bioresour. Technol., 88: 251-254.

Miller, G.L. 1959. Use of dinitrosalicylic acid reagent for determination of reducing sugar. Anal. Chem.., 31(3): 426-428.

Palaniyappan, M., Vijayagopal, V., Renukal, V., Viswanathan, R. and T.
Viruthagiri. 2009. "Screening of natural substrates and optimization of operating variables on the production of pectinase by submerged fermentation using Aspergillus niger MTCC 281," African J. Biotechnol., 8(4): 682-686.

Pandey A. 2003. Solid-state fermentation, Biochem. Eng. J., 13: 81-84.

Rao, M.B., Tanksale, A.M., Gathge, M.S. and Deshpande, V.V. 1998. Molecular and biotechnological aspects of microbial proteases. Microbiol. Mol. Biol. Rev., 62(3): 597-635.

Rombouts, F.M. and Pilnik, W. 1980. Pectic enzymes. Economic microbial., 5: 228282.

Sharma, Neeta Raj. et. al. 2011. "Insight Microbiology,"Insight, 1(1).

Sidhu, G.S., Sharma, P., Chakrabarti, T., and Gupta, J.K. 1997. "Strain improvement for the production of a thermostable $\alpha$ amylase," Enzyme and Microbial Technol., 21(7): 525-530.

Sudharhsan, S., Senthilkumar, S. and Ranjith, K. 2007. "Physical and nutritional factors affecting the production of amylase from species of bacillus isolated from spoiled food waste," African J. Biotechnol., 6(4): 430-435.

\section{How to cite this article:}

Sanjay Patel, Dipika Pandya and S.A. Bhatt. 2016. Optimization of Fermentation Processes for Higher Poly Galacturonase Production from Various Soil Bacteria. Int.J.Curr.Microbiol.App.Sci. 5(8): 309-315. doi: http://dx.doi.org/10.20546/ijcmas.2016.508.033 